\title{
Long noncoding RNAs as potential biomarkers in retinoblastoma: a systematic review and meta-analysis
}

Jiali Wu', Dashi Qian² and Xiaodong Sun $1,3,4,5,6^{*}$ (D)

\begin{abstract}
Background: Retinoblastoma is the most common malignant rare intraocular tumor of childhood. Long noncoding RNAs (IncRNAs) have been reported participating in its progression, but their significance remains inconclusive. We conducted this systematic review and meta-analysis to explore specific IncRNA biomarker in patients with retinoblastoma.

Materials and methods: Eligible articles were searched from the Pubmed, Web of Science, Embase and the Cochrane library. Hazard ratios (HRs) and odds ratios (ORs) were extracted or calculated to evaluate the relationship between IncRNAs and retinoblastoma. The meta-analysis part was conducted with STATA v.15 software.

Results: A total of 9 articles with 834 retinoblastoma patients are yielded. Heterogeneity among HRs of overall survival (OS) is notably high $\left(I^{2}=91.3 \%, p<0.001\right)$. Subgroup analysis suggests that elevated expression of IncRNA BDNF-AS and MT1JP are favorable factors in OS (pooled $\mathrm{HR}=1.89,95 \% \mathrm{Cl} 1.72-2.07, \mathrm{I}^{2}=0 \%$ ). Six articles included optic nerve invasion as a clinicopathological outcome and showed a notable correlation (pooled $\mathrm{HR}=2.38,95 \% \mathrm{Cl}$ $\left.1.26-3.50, I^{2}=0.0 \%\right)$. We validate our analysis via the public dataset and also sum up the studies of IncRNA BDNF-AS and MT1.JP in other cancers.
\end{abstract}

Conclusion: Differential expression of IncRNAs has been reported in retinoblastoma. Some of them showed potential in retinoblastoma prognosis and progression.

Keywords: LncRNA, Retinoblastoma, Meta-analysis, Prognostic

\section{Backgrounds}

Retinoblastoma is the most common intraocular rare malignant tumor in children [1]. The estimated incidence is approximately 8000 new cases and 3000 deaths in the world annually $[2,3]$. Retinoblastoma is not lifethreatening as long as being diagnosed early enough and treated appropriately. However, in developing countries, the situation is quite critical, probably due to rather

\footnotetext{
${ }^{*}$ Correspondence: xdsun@sjtu.edu.cn

${ }^{1}$ Department of Ophthalmology, Shanghai General Hospital (Shanghai First People's Hospital), Shanghai Jiao Tong University, School of Medicine, Shanghai 200080, China

Full list of author information is available at the end of the article
}

high birth rates and limited medical resources. Approximately $40-70 \%$ of patients died in some Asian and African countries [4]. The largest hospital in South Western China used to conduct a retrospective study and found the majority of patients presented at advanced stage [5]. Late diagnosis leads to delayed treatment, which usually means increasing metastasis and decreasing survival rate [6]. Once proliferating into brain through optic nerve, the damage becomes irreparable and fatal. Therefore, effective and early diagnosis is particularly crucial. Exploring novel diagnostic and therapeutic signatures that can be used in retinoblastoma management deserves more study to achieve the aim of eradicating retinoblastoma in the future decade.

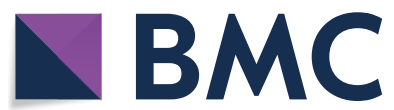

(c) The Author(s) 2020. This article is licensed under a Creative Commons Attribution 4.0 International License, which permits use, sharing, adaptation, distribution and reproduction in any medium or format, as long as you give appropriate credit to the original author(s) and the source, provide a link to the Creative Commons licence, and indicate if changes were made. The images or other third party material in this article are included in the article's Creative Commons licence, unless indicated otherwise in a credit line to the material. If material is not included in the article's Creative Commons licence and your intended use is not permitted by statutory regulation or exceeds the permitted use, you will need to obtain permission directly from the copyright holder. To view a copy of this licence, visit http://creativeco mmons.org/licenses/by/4.0/. The Creative Commons Public Domain Dedication waiver (http://creativecommons.org/publicdomain/ zero/1.0/) applies to the data made available in this article, unless otherwise stated in a credit line to the data. 
Long noncoding RNAs (lncRNAs) are a group of noncoding RNAs that are greater than 200 nucleotides in length. They are widely reported to contribute to tumor progression including proliferation, migration and invasion [7]. Some of them have already been implicated as tumor biomarkers. For example, lncRNA MALAT1 can be applied to predict early and metastatic lung cancers [8]. It is also reported as a cancer suppressor. Professor Ma from famous MD Anderson Cancer Center found it suppressing the metastasis of breast cancer cells [9]. Similarly, emerging studies demonstrate the differential expression of lncRNAs between retinoblastoma and normal tissues, leading us to consider whether they can be potential approaches for early diagnosis and clinical outcomes.

Therefore, we conducted this meta-analysis to evaluate the function of candidate lncRNAs in retinoblastoma in order to find potential prognostic lncRNA markers for further investigation.

\section{Materials and methods Literature search}

Two investigators (WJL and QDS) performed this systematic literature search independently through Pubmed, Web of Science, Embase and the Cochrane library (from September 10, 2019 to October 10, 2019). The search terms were used with various conjunctions: ("IncRNA" OR "lincRNA" OR "long noncoding RNA" OR "long untranslated RNA" OR "long intergenic noncoding RNA") AND ("retinoblastoma"). Related citations of every included article were also manually examined. We only included articles in English language and agreement were achieved on each articles by both of the investigators after careful screening and discussion.

\section{Selection criteria}

Studies from the literature search were included based on the following conditions: (1) LncRNA expression was detected in retinoblastoma tissues; (2) the retinoblastoma tissues were all pathologically diagnosed and classified by $\geq 2$ pathologists; (3) the relationship between lncRNA expression and retinoblastoma patient prognosis was investigated, including overall survival and other related clinicopathological parameters; and (4) sufficient data were provided for the hazard ratio (HR) and the 95\% confidence interval (95\% CI) of survival and clinicopathological parameters. Meanwhile, unsuited studies were excluded if they are: (1) animal studies and reviews; (2) studies based on patient blood and serum; (3) duplicate records; and (4) studies without other sufficient data.

\section{Data extraction and quality assessment}

Two investigators extracted requisite information from each eligible study: first authors, publication year, lncRNA type and expression, sample size, sample type, the HR and 95\% CI of lncRNA for survival. Engauge Digitizer v.10.11 software and Tierney's spreadsheet were utilized to obtain the HR when it was not offered directly. HR from multivariate analysis was preferred over that from the univariate analysis as it accounted for confounding factors. Quality assessment of each eligible study was performed based on the acknowledged Newcastle-Ottawa Quality Assessment Scale (NOS) with scores ranging from zero to nine. A study with a NOS score higher than 6 is regarded as high quality.

\section{Data processing}

Datasets of GSE125903 were normalized before calculation. Differential expressing genes (DEGs) were analyzed by $\mathrm{R}$ packages of "limma" (http://www.bioco nductor.org/packages/release/bioc/html/limma.html). Limma is an open source package on Bioconductor platform. We use Benjamini-Hochberg method to get the adjusted $\mathrm{p}$ values, Imfit and eBayes functions to get the different expressed genes. The cutoff of adjusted $\mathrm{p}$ values was set to 0.05 and the cutoff of $|\log 2 \mathrm{FC}|$ was 1.5 . The genes which meet the two conditions above were identified as DEGs. We use ggpubr and ggthemes to draw volcano plots for each datasets, with an $\mathrm{x}$ axis of " $\log 2$ (Fold Change)" and an y axis of "- $\log 10$ (Adjust p-value)". The heatmap was done by R package of "pheatmap".

\section{Statistical analysis}

As different lncRNAs act differently in retinoblastoma, pooling HRs directly would lead to great heterogeneity, we assessed the heterogeneity among studies and conducted the subgroup analysis of HRs based on different lncRNAs. Heterogeneity of the results was estimated by the $\mathrm{Q}$ test and $\mathrm{I}^{2}$ statistics. We selected the random pooling model, to be on the safe side. HR $>1$ suggested a significant association of IncRNA overexpression with poor survival, and $H R<1$ indicated that high lncRNA expression predicted long survival. All these calculations were completed with STATA v.15 software.

\section{Results}

\section{Characteristics of the included studies}

As shown in Fig. 1, a total of 209 articles were identified from online resources. Among them, 9 articles with 834 retinoblastoma patients published between 2015 and 2019 in China were included in our analysis. The relevant lncRNAs include PVT1 [10], AFAP1-AS1 [11], HOTAIR [12], BANCR [13], H19 [14], DANCR [15], LINC00202 


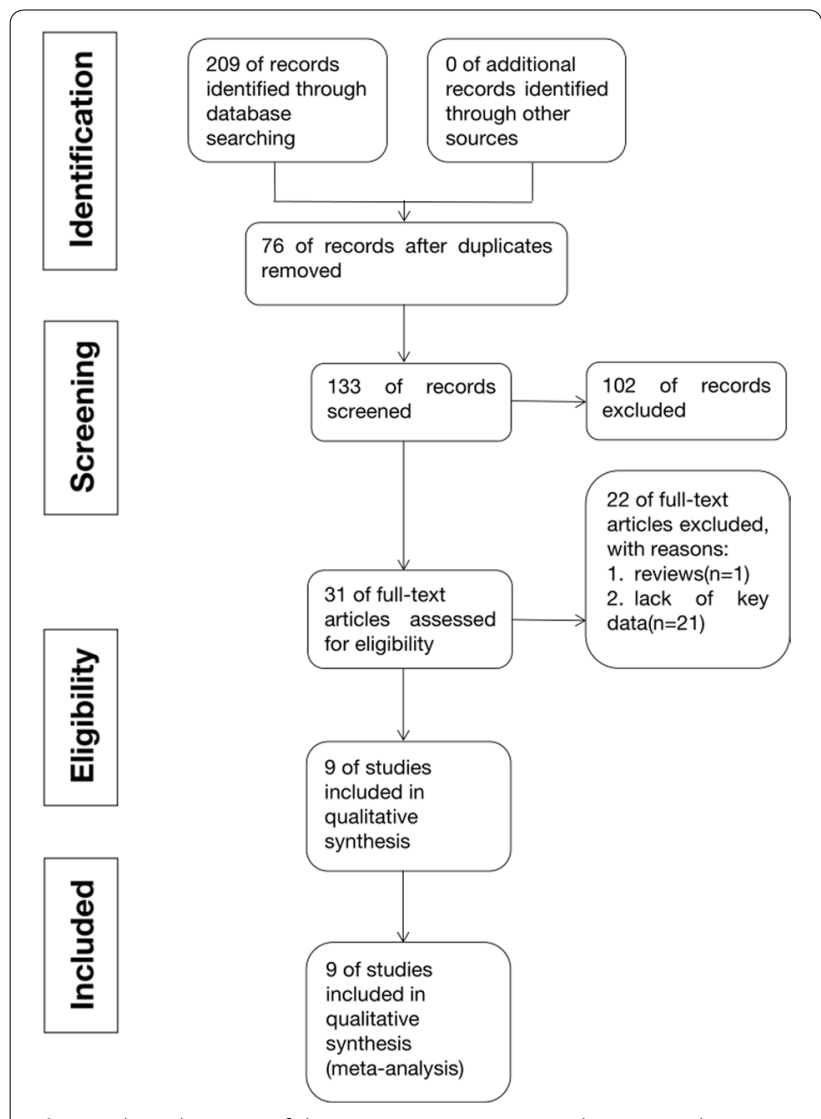

Fig. 1 Flow diagram of this systematic review and meta-analysis

[16], MT1JP [17] and BDNF-AS [18]. 7 of them used OS as a main outcome and 2 of them used both overall survival (OS) and disease-free survival (DFS) for survival analysis. OS means the percentage of patients still alive at the endpoint while DFS means the percentage of patients without any symptoms of the retinoblastoma. The expression was detected by quantitative polymerase chain reaction (qPCR) in human retinoblastoma tissue specimens. More than half of the studies included applied median value as the cut-off value to stratify patients into high of low expression group. 6 of the articles reported the HRs directly while the remaining used survival curves. Most included articles are of high quality with a rather high NOS score. More details are shown in Table 1.

\section{The relationship between IncRNAs and patient survival} LncRNAs PVT1, AFAP10AS1, HOTAIR, BANCR, H19, DANCR and LINC00202 were up-regulated in retinoblastoma tissues while MT1JP and BDNF-AS were down-regulated. Owing to the rather significant heterogeneity $\left(\mathrm{I}^{2}=91.3 \%, \mathrm{p}<0.001\right)$, a random model was employed to calculate the $95 \% \mathrm{CI}$ and pooled HR. To decrease the heterogeneity, we performed subgroup analysis. It suggested no significance between overall high expression and poor OS (pooled $\mathrm{HR}=1.31$, 95\% CI 0.43-2.20, $\mathrm{I}^{2}=51.8 \%$; Fig. 2). Individually, high expression of lncRNA AFAP1-AS1 $(\mathrm{HR}=3.6,95 \% \mathrm{CI}$ 1.33-9.72), BANCR ( $\mathrm{HR}=2.9,95 \%$ CI $1.05-8.04)$ and $\mathrm{H} 19$ ( $\mathrm{HR}=2.91,95 \% \mathrm{CI} 1.02-8.45)$ are obviously associated with worse OS. In contrast, increased levels of LncRNA BDNF-AS and MT1JP were favorable factors in OS (pooled HR $=1.89,95 \%$ CI 1.72-2.07, $\mathrm{I}^{2}=0 \%$; Fig. 2). Both LncRNA BDNF-AS and MT1JP have been reported decreased in quite a few cancers including gastric cancer, bladder cancer and lung cancer, suggesting their potential role as a rather broad and sensitive tumor suppresser. Two of the articles included provided DFS data and we also found no significance between their overall high expression and poor DFS (pooled $\mathrm{HR}=1.98,95 \% \mathrm{CI}$ 0.87-3.09, $\mathrm{I}^{2}=0.0 \%$; Fig. 3).

\section{The relationship between IncRNAs and clinicopathological outcomes}

The clinicopathological outcomes mentioned by these 9 articles include tumor size, choroidal invasion, gender, laterality, optic nerve invasion and pathologic grade. All lncRNAs had no remarkable relationship with tumor size, choroidal invasion, gender, laterality and pathologic grade (tumor size: $\mathrm{p}=0.209$, choroidal invasion: $\mathrm{p}=0.996$, gender: $\mathrm{p}=0.844$, laterality: $\mathrm{p}=0.823$ and pathologic grade: $\mathrm{p}=0.005)$. LncRNA HOTAIR was significantly correlated with larger tumor size $(\mathrm{HR}=5$, 95\% CI 2.86-9.09). Besides, it also related with TNM classification $(\mathrm{HR}=1.89 \%, 95 \% \mathrm{CI} 1.06-3.33) .6$ articles included applied optic nerve invasion as a clinicopathological outcome and showed a notable correlation (pooled $\mathrm{HR}=2.38,95 \%$ CI 1.26-3.50, $\mathrm{I}^{2}=0.0 \%$; Fig. 4). Optic nerve invasion is known as a major risk factor for retinoblastoma mortality [19]. There is a relation between the extent of invasion and metastasis. Once the invasion come to the cut end of the optic nerve, the mortality increases to $50 \sim 80 \%$ [20]. However, it remains unsolved how to predict the invasion before it happens or evaluate the involvement during development [21]. Probably these three lncRNAs can provide some new hints. More details are shown in Fig. 5.

\section{Publication bias and sensitivity analysis}

Egger's publication bias plot and Begg's funnel plot were constructed to explore the potential publication bias in this study. Two plots did not display apparent asymmetry (Egger's test: $\mathrm{p}=0.749$ and Begg's test: $\mathrm{p}=0.553$ ), which showed no significant publication bias (Fig. 5). In addition, the sensitivity analysis suggested the robustness of 


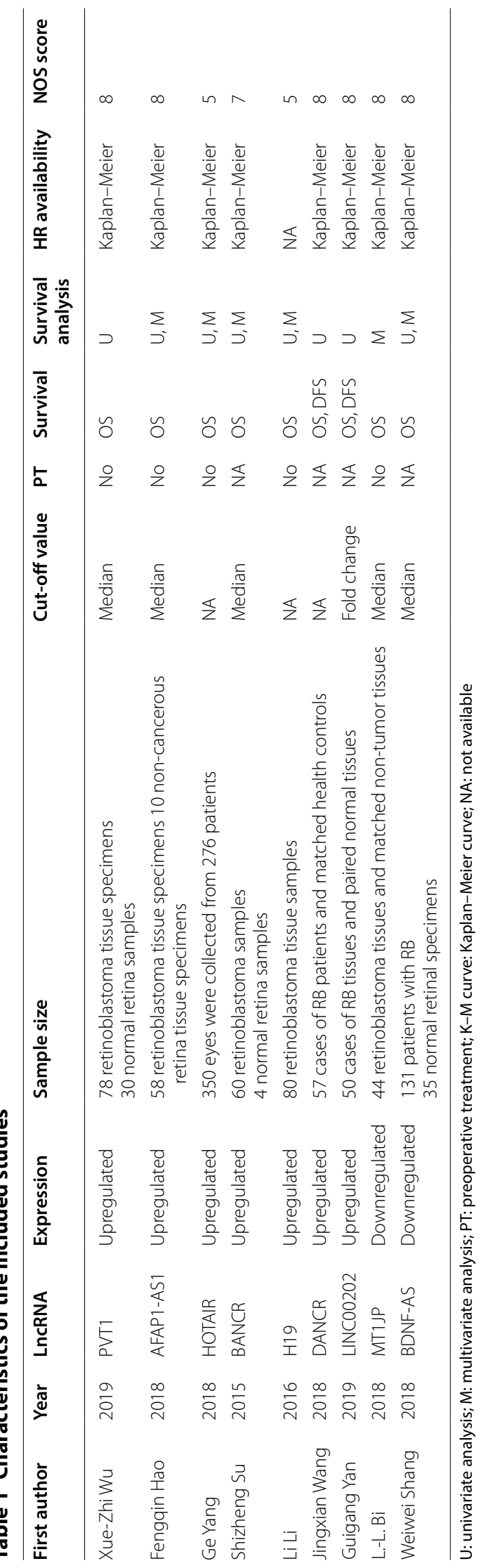




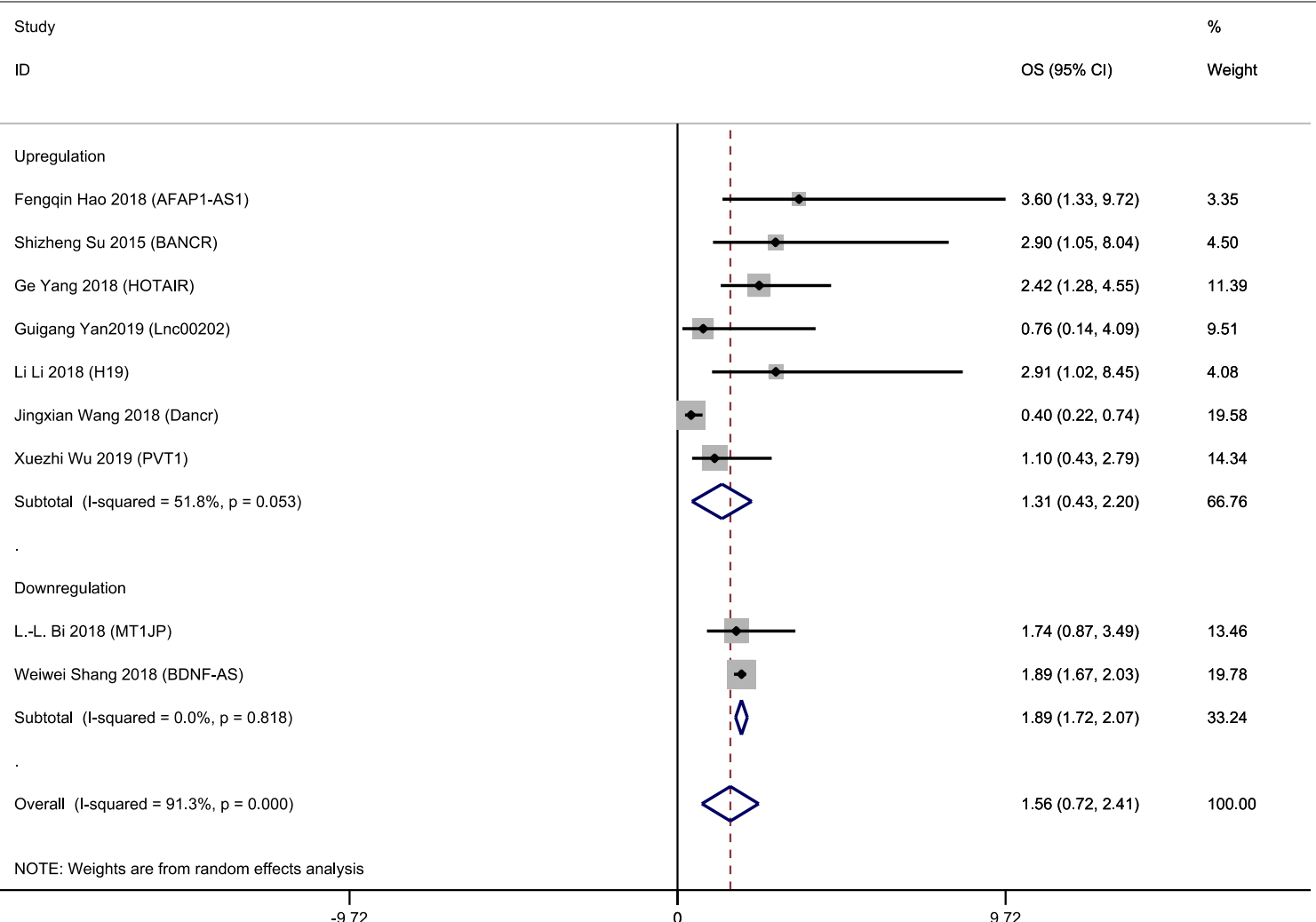

Fig. 2 Subgroup analysis of OS by IncRNA expression in retinoblastoma

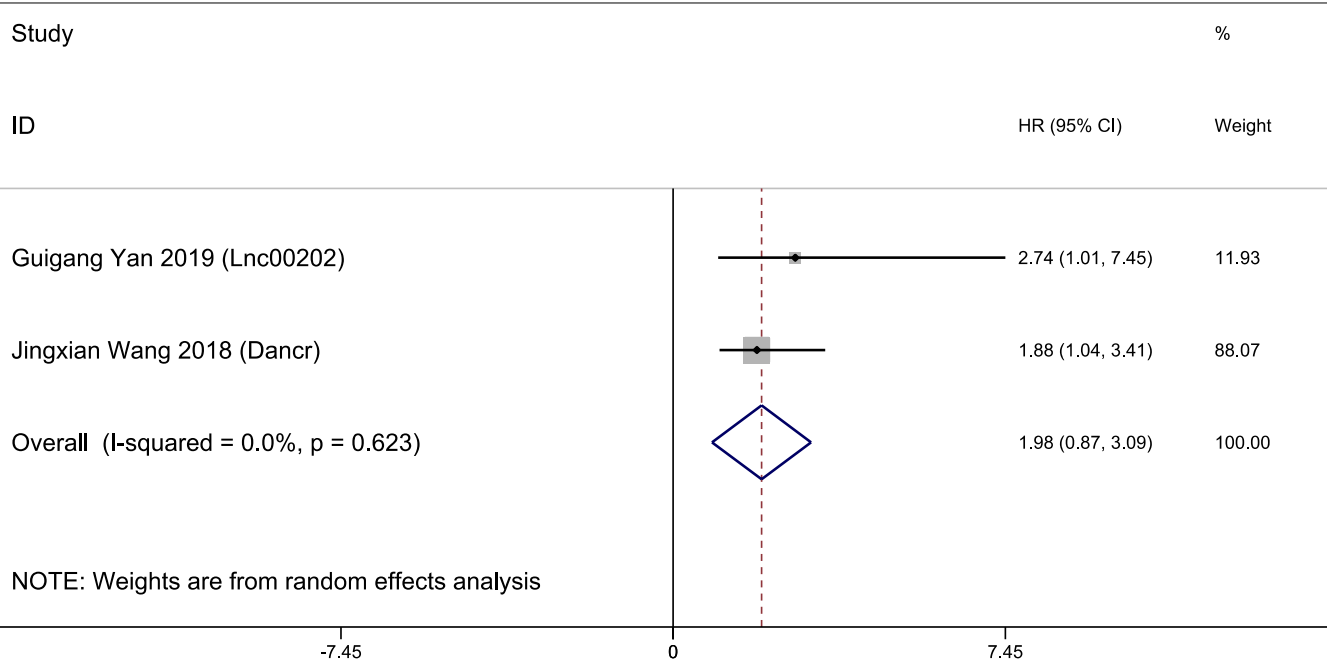

Fig. 3 Forest plot of HRs of high IncRNA expression and DFS

the results because eliminating any study did not change the results significantly (Fig. 6).
Action mechanisms of IncRNAs in retinoblastom

Furthermore, we concentrated on potential targets and pathways of these IncRNAs included in our study (Table 2). Most of them sponge with microRNA to influence retinoblastoma progression. 
a

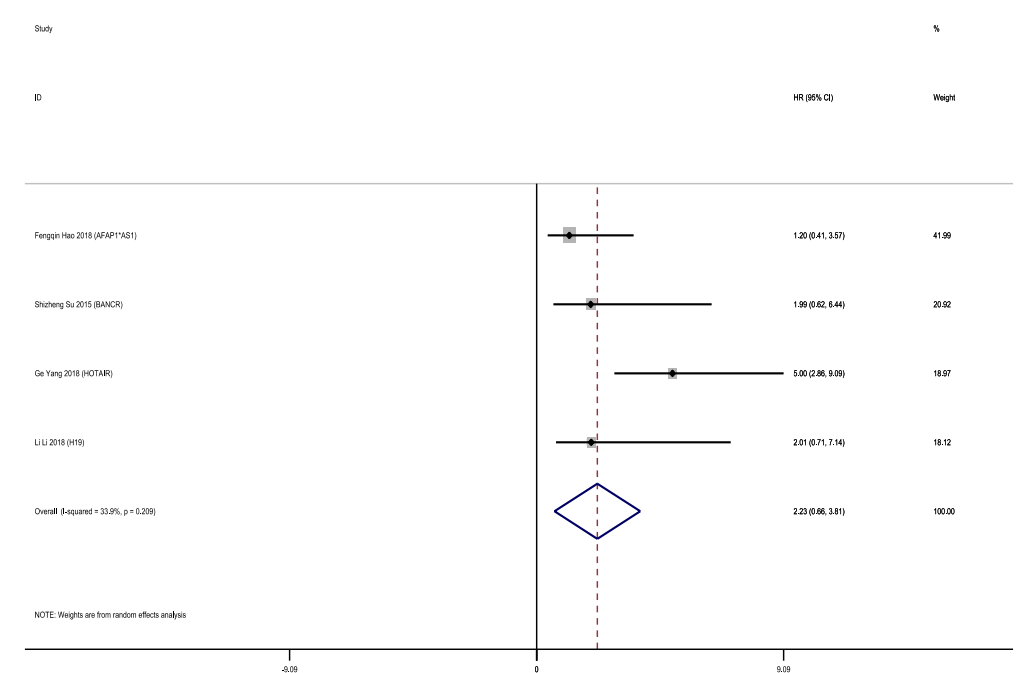

b

sidoly

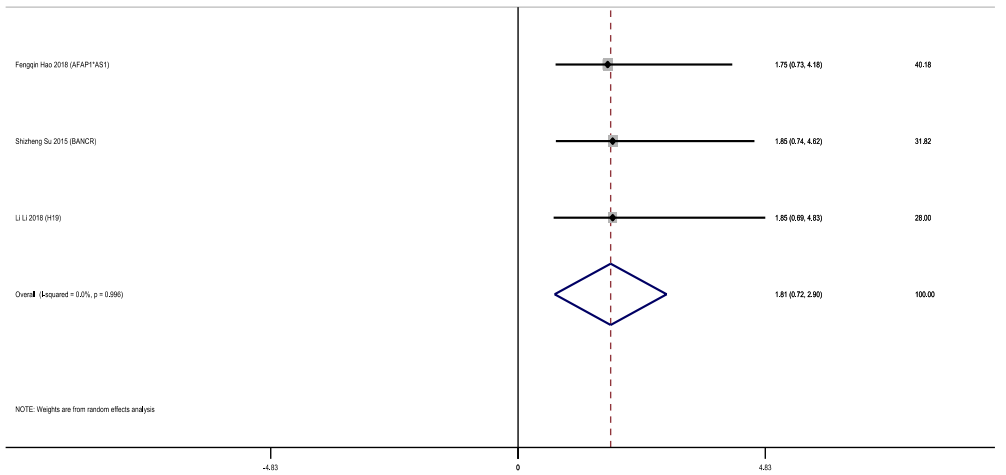

c

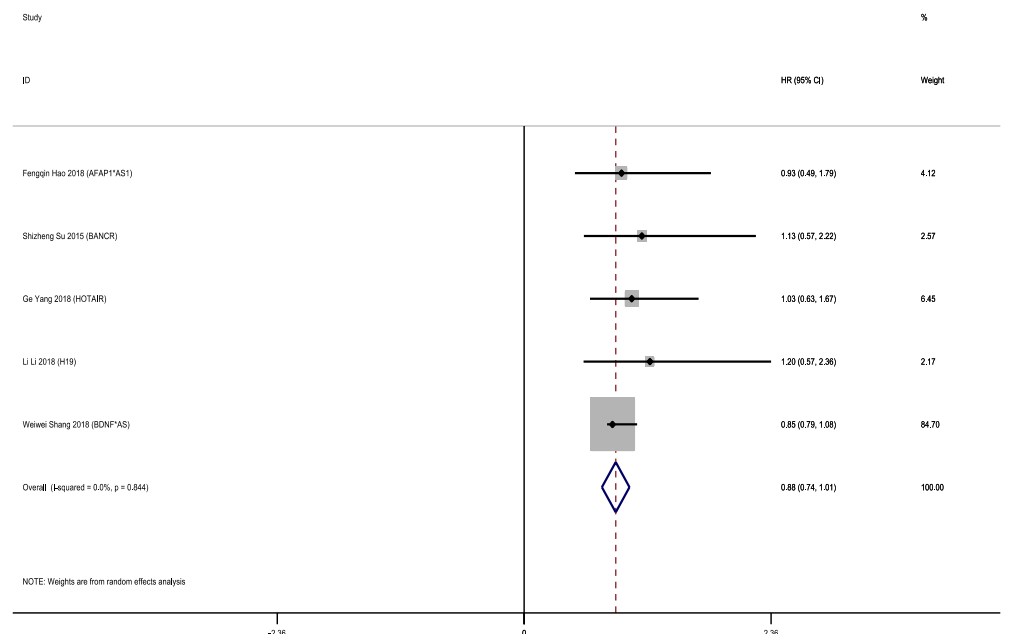

Fig. 4 Forest plots of the association of IncRNA expression with clinicopathological parameters: a tumor size; $\mathbf{b}$ choroidal invasion; c gender; $\mathbf{d}$ laterality; e optic nerve invasion and $\mathbf{f}$ pathologic grade 
d

。

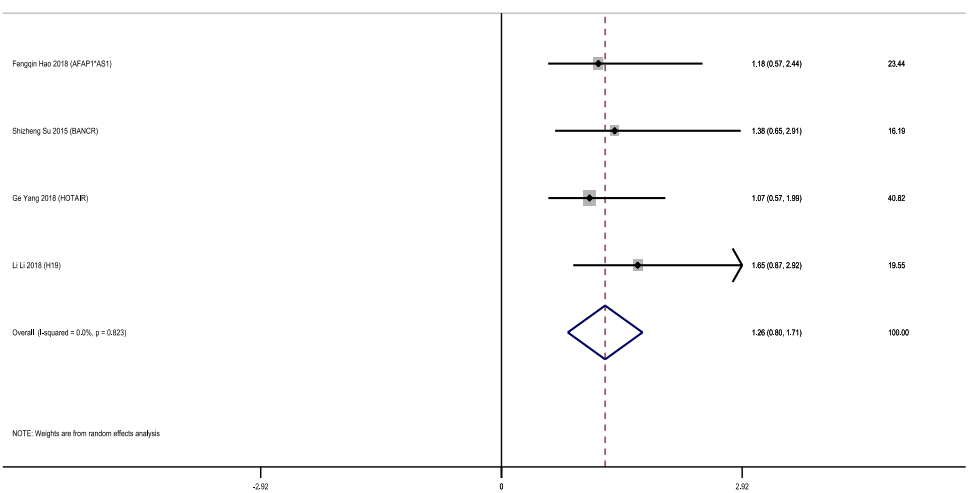

e

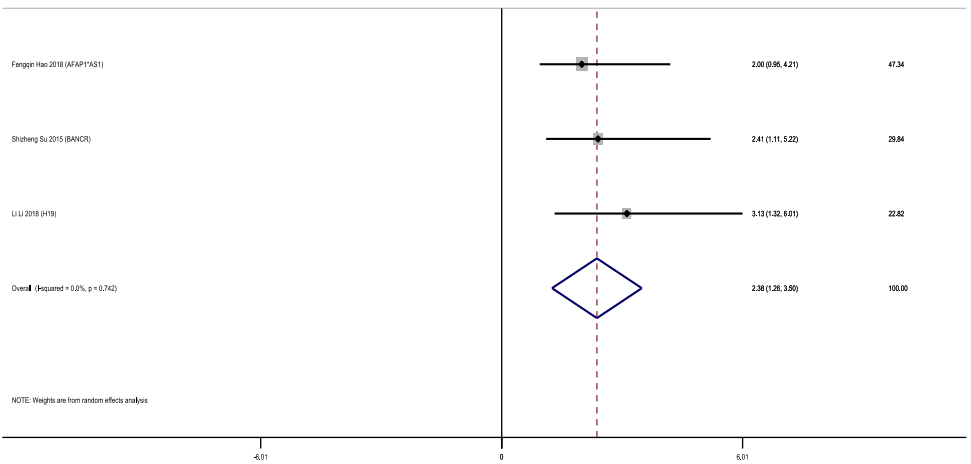

f suty

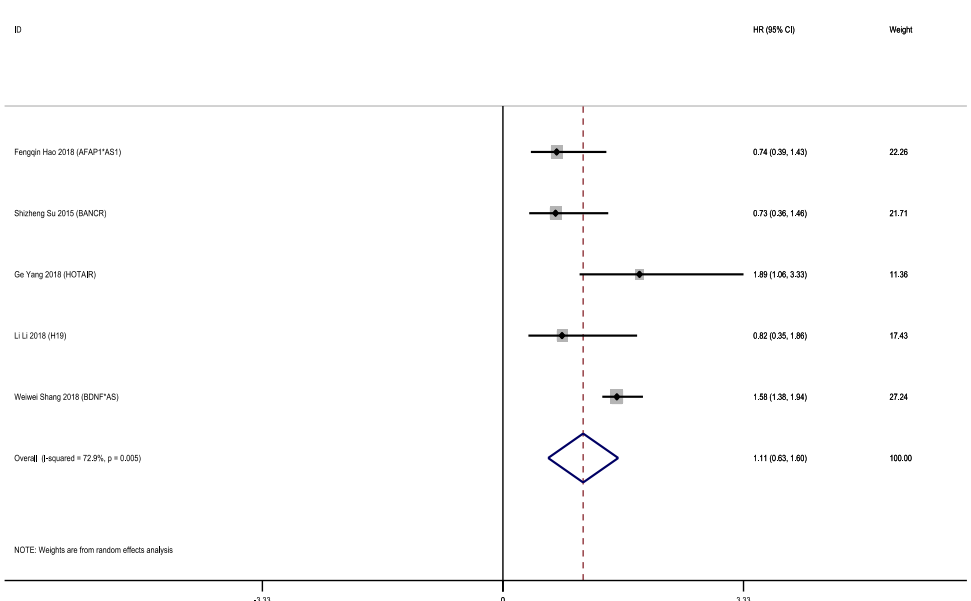

Fig. 4 continued 

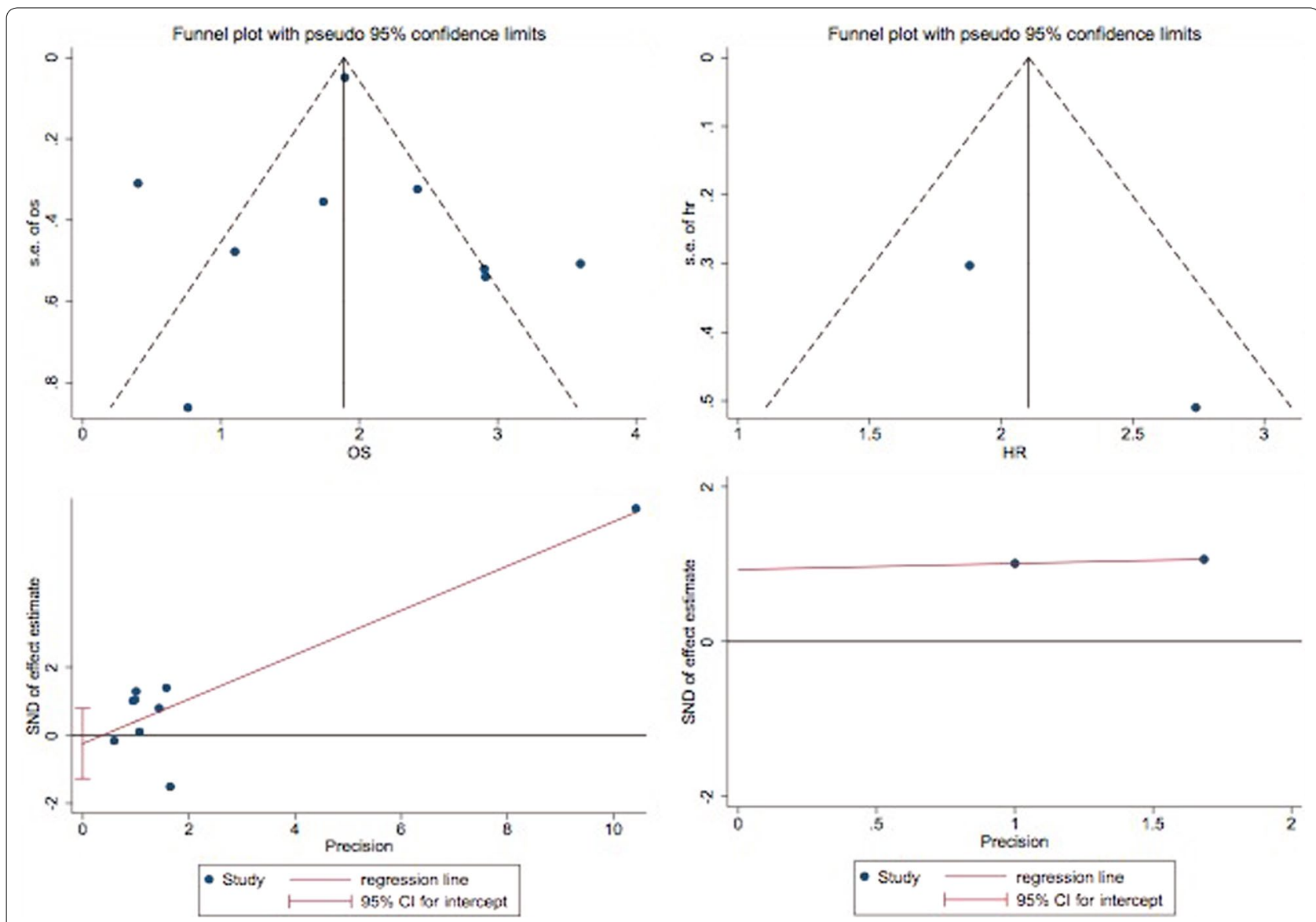

Fig. 5 Tests for publication bias of OS

Meta-analysis random-effects estimates (linear form) Study ommited

Fengqin Hao 2018 (AFAP1-AS1)

Shizheng Su 2015 (BANCR)

Ge Yang 2018 (HOTAIR)

Guigang Yan2019 (Lnc00202)

L.-L. Bi 2018 (MT1JP)

Li Li 2018 (H19)

Weiwei Shang 2018 (BDNF-AS)

Jingxian Wang 2018 (Dancr)

Xuezhi Wu 2019 (PVT1)
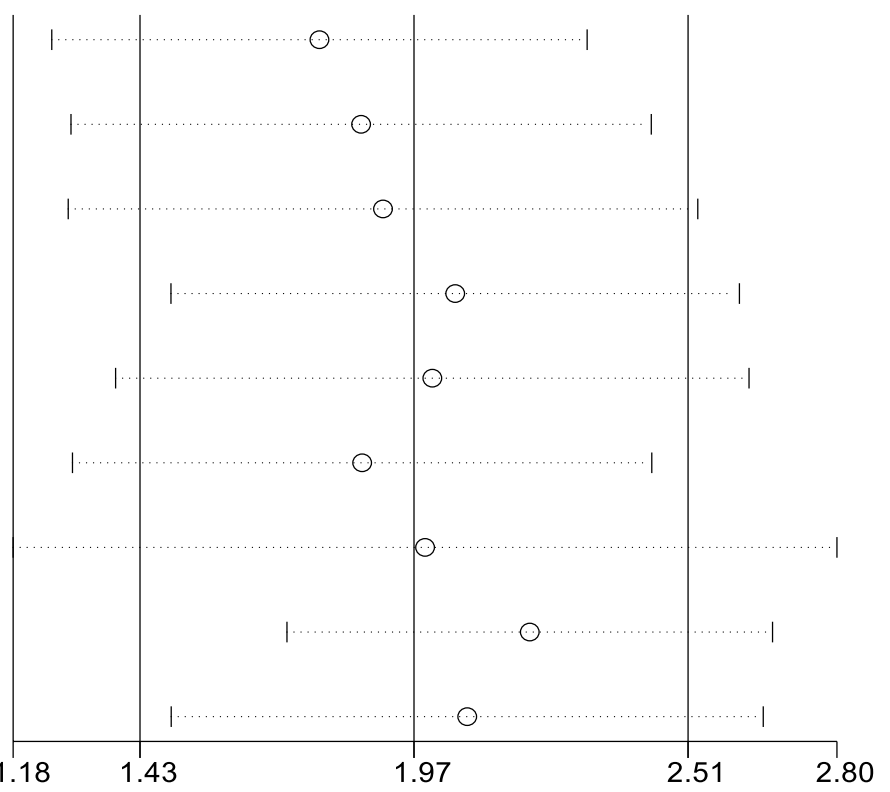

Fig. 6 Sensitivity analysis of studies on OS 
Table 2 The potential targets and function of the IncRNAs included in our study

\begin{tabular}{|c|c|c|c|c|}
\hline First author & LncRNA type & Expression & Potential target(s) & Pathways \\
\hline Xuezhi Wu & PVT1 & Upregulated & $\operatorname{miR}-488-3 p$ & $\uparrow$ Cancer progression; $\downarrow$ cell apoptosis; $\downarrow$ G1/S arrest; $\uparrow$ Migration and invasion \\
\hline Fengqin Hao & AFAP1-AS1 & Upregulated & NA & $\uparrow$ Cell proliferation; $\uparrow$ cell cycle progression; $\uparrow$ cell migration and invasion \\
\hline Ge Yang & HOTAIR & Upregulated & $\operatorname{miR}-613$ & $\begin{array}{l}\downarrow \text { Cell apoptosis; } \\
\uparrow \text { Cell proliferation and cell viability }\end{array}$ \\
\hline Shizheng Su & BANCR & Upregulated & NA & $\begin{array}{l}\uparrow \text { Cell proliferation, migration and invasion; } \\
\uparrow \text { Retinoblastoma progression }\end{array}$ \\
\hline $\mathrm{Li} \mathrm{Li}$ & $\mathrm{H} 19$ & Upregulated & NA & $\begin{array}{l}\uparrow \text { Cell proliferation, apoptosis; migration and invasion; } \uparrow \text { Retinoblastoma } \\
\text { progression }\end{array}$ \\
\hline Jingxian Wang & DANCR & Upregulated & miR-34c; miR-613 & $\begin{array}{l}\uparrow \text { Proliferation, migration, invasion, and epithelial-mesenchymal transition } \\
(\text { EMT); } \uparrow \text { tumor growth }\end{array}$ \\
\hline Guigang Yan & LINC00202 & Upregulated & miR-3619-5p & $\uparrow$ Cell proliferation, migration and invasion \\
\hline L.-L. Bi & MT1JP & Downregulated & Wnt/ $\beta$-Catenin & $\begin{array}{l}\uparrow \mathrm{G} 0 / \mathrm{G} 1 ; \uparrow \text { cell apoptosis; } \\
\downarrow \text { Cell proliferation, migration and invasion }\end{array}$ \\
\hline Weiwei Shang & BDNF-AS & Downregulaed & NA & $\begin{array}{l}\downarrow \text { Cancer proliferation and migration; } \\
\uparrow \text { Cell-cycle arrest }\end{array}$ \\
\hline
\end{tabular}

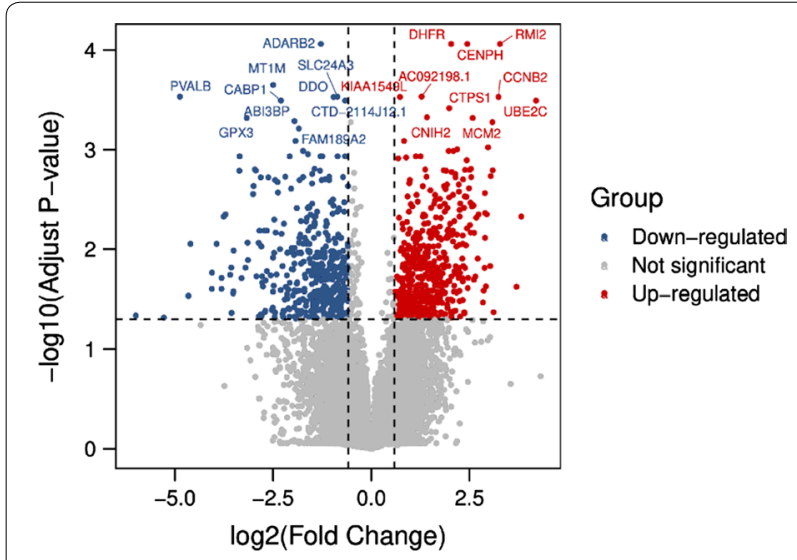

Fig. 7 Volcano plot of GSE125903

\section{Validation of the candidate IncRNAs}

Right now, we have figured out two potential lncRNAs. For the further validation, we searched the public datasets and found GSE125903 (Fig. 7). It was the first transcriptomic report on pediatric retinoblastoma tumor based on 7 retinoblastoma tissue and 3 control retina tissue [22]. We downloaded its original data and analyzed the 9 IncRNAs discussed in our analysis. The results were showed in a heatmap (Fig. 8). LncRNA MT1JP and BDNF-AS were slightly decreased in retinoblastoma tissues, which was consistent with our analysis. In addition, lncRNA DANCR, PVT1 and H19 also showed significant changes, which deserved more attention.

\section{Discussion}

Retinoblastoma accounts for 3\% of all childhood cancers and is one of the most malignant intraocular tumors [23]. Despite of the development of overall health care, the mortality of retinoblastoma still remains relatively high in Asia, especially in China, partly due to the likely delayed diagnosis [24]. Thus, looking for suitable and sensitive screening biomarkers would benefit clinicians a lot in taking actions in time.

In the past few years, various lncRNAs have been reported in the pathogenesis and progression of retinoblastoma. Last year, Pluousiou et al. did a comprehensive review of lncRNAs involved in retinoblastoma [25], however, right now, no study has described the relation between lncRNAs and patient survival or clinicopathological outcomes systematically.

In our study, we analyzed the role of 9 lncRNAs in retinoblastoma survival and clinical indicators. Seven upregulated lncRNAs showed no overall remarkable relationship with OS. Two downregulated lncRNAs: BDNF-AS and MT1JP predicted favorable OS. We further searched the public dataset to validate our analysis. However, we also found both of them have been reported in quite a few cancers (Table 3), thus their specificity for retinoblastoma needs further verification. High expression of Lnc00202 and BANCR both indicated poorer DFS while taken together, this result is not significant.

Among the 5 main clinicopathological parameters, lncRNAs had significant relation with optic nerve invasion. Optic nerve invasion is one of the most significant risk factor for eye enucleation and mortality and with the increase of involvement, the mortality risk increases, too. Predicting or managing the development 


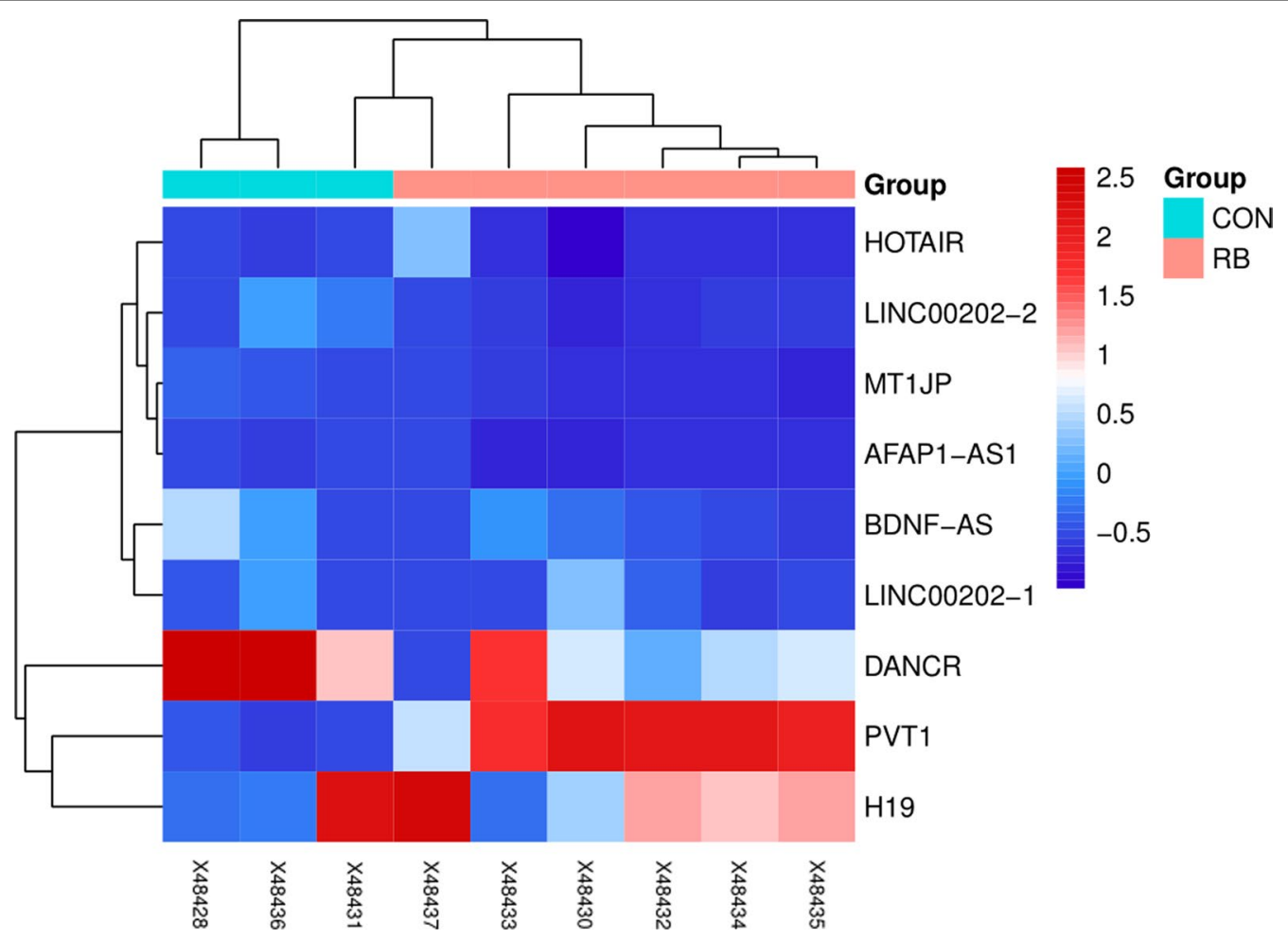

Fig. 8 Heatmap of 9 IncRNAs in GSE125903

Table 3 Studies including IncRNA BDNF-AS and MT1JP in cancers

\begin{tabular}{|c|c|c|c|c|c|c|}
\hline First author & Year & Diseases & Sample size & Assay & Expression & Potential targets \\
\hline \multicolumn{7}{|l|}{ LncRNA BDNF-AS } \\
\hline Huaying Zhao [26] & 2018 & Oesophageal cancer & 45 pairs of surgical primary EC tissues & qPCR & Downregulated & miR-214 \\
\hline Huimin Zhang [27] & 2018 & Cervical cancer & 125 pairs of cancer cervix tissues & qPCR & Downregulated & BDNF \\
\hline Hui Zhi [28] & 2019 & Colorectal cancer (CRC) & 20 pairs of $C R C$ tissues & qPCR & Downregulated & GSK-3ß \\
\hline Wensheng Li [29] & 2018 & Prostate cancer (CaP) & 141 pairs of surgical CaP tissues & qPCR & Downregulated & NA \\
\hline Qiang Huang [30] & 2018 & Osteosarcoma (OS) & $\begin{array}{l}114 \text { OS samples } \\
35 \text { paired non-cancerous samples }\end{array}$ & qPCR & Downregulated & cleaved caspase-3 \\
\hline Farbod Esfandi [30] & 2019 & Gastric cancer & 30 pairs of cancer specimens & qPCR & Downregulated & NA \\
\hline \multicolumn{7}{|l|}{ LncRNA MT1JP } \\
\hline Ying Xu [31] & 2018 & Gastric cancer & $\begin{array}{l}99 \text { pairs of GC tissues and neighboring } \\
\text { noncancerous tissues }\end{array}$ & qPCR & Downregulated & MT1JP/MiR-214-3p/RUNX3 \\
\hline Gang Zhang [32] & 2018 & Gastric cancer & $\begin{array}{l}5 \text { pairs of normal and GC tissues }+75 \\
\text { paired tissues }\end{array}$ & $\mathrm{qPCR}$ & Downregulated & MT1JP/MiR-92a-3p/FBXW7 \\
\hline Donglei Zhu [33] & 2019 & Breast cancer & $\begin{array}{l}56 \text { paired samples of breast cancer tissue } \\
\text { and adjacent normal breast tissues }\end{array}$ & qPCR & Downregulated & miR-24-3p \\
\hline Haifeng Yu [34] & 2019 & Bladder tumor & $\begin{array}{l}35 \text { paired samples of bladder cancer sam- } \\
\text { ples and adjacent no-tumor samples }\end{array}$ & qPCR & Downregulated & miR-214-3p \\
\hline Jiyong Ma [35] & 2019 & Lung cancer & $\begin{array}{l}30 \text { non-small cell lung cancer (NSCLC) } \\
\text { and adjacent normal tissues }\end{array}$ & qPCR & Downregulated & miRNA-423-3p/Bim \\
\hline
\end{tabular}


of nerve invasion remains a demanding task [36] while lncRNAs might be somewhat of benefit.

We also summed up the mechanisms of lncRNAs in retinoblastoma, which might be helpful for further comprehensive recognition.

Limitations of our meta-analysis include: (1) All of the studies included are conducted in China. We propose studies outside China to compare and confirm our results. (2) Sample size of most studies included are rather limited and larger researches are still needed. (3) Some of the studies did not provide HRs directly and we collected the necessary information from survival curves, which might be not so accurate. (4) We only collected the targets and pathways of lncRNAs studied in the articles we included. More regulatory mechanisms are available in articles we did not enrolled.

\section{Conclusions}

Our study systematically reviewed and analyzed the abnormally expressed lncRNAs in retinoblastoma. Based on all eligible evidence, we found two lncRNAs:BDNF-AS and MT1JP as potential prognostic biomarker for retinoblastoma. Considering our existed limitations and further needs, larger-scale prospective investigations are warranted for validation.

\section{Acknowledgements}

Not applicable.

\section{Authors' contributions}

JW and DQ collected the studies and analyzed the data. JW wrote the script. XS revised the final paper. All authors read and approved the final manuscript.

\section{Funding}

This study was supported by the National Natural Science Foundation of China (Key Program) $(81730026,81425006)$, Frontier Project of Shanghai Hospital Development Center (SHDC12016105), Science and Technology Commission of Shanghai Municipality(17411953000, 16140900800, 0303N17001).

\section{Availability of data and materials}

All data are included in this article.

Ethics approval and consent to participate

Not applicable.

\section{Consent for publication}

Not applicable.

\section{Competing interests}

The authors declare that they have no competing interests.

\footnotetext{
Author details

${ }^{1}$ Department of Ophthalmology, Shanghai General Hospital (Shanghai First People's Hospital), Shanghai Jiao Tong University, School of Medicine, Shanghai 200080, China. ${ }^{2}$ Department of Translation and Interpreting, Shanghai Jiao Tong University School of Foreign Language, Shanghai, China. ${ }^{3}$ Shanghai Key Laboratory of Fundus Diseases, Shanghai 200080, China. ${ }^{4}$ Shanghai Engineering Center for Visual Science and Photomedicine, Shanghai 200080, China.

${ }^{5}$ National Clinical Research Center for Eye Diseases, Shanghai 200080, China.

${ }^{6}$ Shanghai engineering center for precise diagnosis and treatment of eye diseases, Shanghai 200080, China.
}

Received: 12 March 2020 Accepted: 18 May 2020

Published online: 29 May 2020

\section{References}

1. Yahaya JJ, Rugwizangoga B, Mremi A, Munema A. Clinicopathological findings of retinoblastoma: a 10-year experience from a tertiary hospital in Kampala, Uganda. J Ophthalmol. 2019;2019:5829284. https://doi. org/10.1155/2019/5829284 (Published 2019 Jun 16).

2. Dimaras H, Corson TW, Cobrinik D, et al. Retinoblastoma. Nat Rev Dis Primers. 2015;1:15021. https://doi.org/10.1038/nrdp.2015.21 (Published 2015 Aug 27).

3. Kivela T. The epidemiological challenge of the most frequent eye cancer: retinoblastoma, an issue of birth and death. Br J Ophthalmol. 2009;93(9):1129-31. https://doi.org/10.1136/bjo.2008.150292.

4. Gudiseva HV, Berry JL, Polski A, Tummina SJ, O'Brien JM. Next-generation technologies and strategies for the management of retinoblastoma. Genes. 2019;10(12):1032. https://doi.org/10.3390/genes10121032 (Published 2019 Dec 11)

5. Gao J, Zeng J, Guo B, et al. Clinical presentation and treatment outcome of retinoblastoma in children of South Western China. Medicine. 2016;95(42):e5204. https://doi.org/10.1097/md.0000000000005204.

6. Dimaras H, Kimani K, Dimba EA, Gronsdahl P, White A, Chan HS. Retinoblastoma. Lancet. 2012;379(9824):1436-46. https://doi.org/10.1016/ S0140-6736(11)61137-9 (ISSN 0140-6736).

7. Li J, Li Z, Zheng W, et al. LnCRNA-ATB: an indispensable cancer-related long noncoding RNA. Cell Prolif. 2017;50:e12381. https://doi.org/10.1111/ cpr.12381.

8. Bhan A, Soleimani M, Mandal SS. Long noncoding RNA and cancer: a new paradigm. Cancer Res. 2017;77(15):3965-81. https://doi. org/10.1158/0008-5472.can-16-2634.

9. Kim J, Piao HL, Kim BJ, et al. Long noncoding RNA MALAT1 suppresses breast cancer metastasis. Nat Genet. 2018;50(12):1705-15. https://doi. org/10.1038/s41588-018-0252-3.

10. Wu XZ, Cui HP, Lv HJ, Feng L. Knockdown of IncRNA PVT1 inhibits retinoblastoma progression by sponging miR-488-3p. Biomed Pharmacother. 2019;112:108627. https://doi.org/10.1016/j.biopha.2019.108627 (ISSN 0753-3322)

11. Hao F, Mou Y, Zhang L, Wang S, Yang Y. LncRNA AFAP1-AS1 is a prognostic biomarker and serves as oncogenic role in retinoblastoma. Biosci Rep. 2018;38(3):BSR20180384. https://doi.org/10.1042/bsr20180384.

12. Yang G, Fu Y, Lu X, Wang M, Dong H, Li Q. LncRNA HOTAIR/miR-613/c-met axis modulated epithelial-mesenchymal transition of retinoblastoma cells. J Cell Mol Med. 2018;22(10):5083-96. https://doi.org/10.1111/ jcmm.13796.

13. Su S, Gao J, Wang T, Wang J, Li H, Wang Z. Long non-coding RNA BANCR regulates growth and metastasis and is associated with poor prognosis in retinoblastoma. Tumor Biol. 2015;36(9):7205-11. https://doi.org/10.1007/ s13277-015-3413-3

14. Li L, Chen W, Wang Y, Tang L, Han M. Long non-coding RNA H19 regulates viability and metastasis, and is upregulated in retinoblastoma. Oncol Lett. 2018;15(6):8424-32. https://doi.org/10.3892/ol.2018.8385.

15. Wang J-X, Yang Y, Li K. Long noncoding RNA DANCR aggravates retinoblastoma through miR-34c and miR-613 by targeting MMP-9. J Cell Physiol. 2018;233:6986-95. https://doi.org/10.1002/jcp.26621.

16. Yan Guigang, Su Yi, Ma Zhao, Yu Lianzhi, Chen Ning. Long noncoding RNA LINC00202 promotes tumor progression by sponging miR3619-5p in retinoblastoma. Cell Struct Funct. 2019;44:51-60. https://doi. org/10.1247/csf.18033.

17. Bi LL, Han F, Zhang XM, Li YY. LncRNA MT1JP acts as a tumor inhibitor via reciprocally regulating $\mathrm{Wnt} /$ beta-catenin pathway in retinoblastoma. Eur Rev Med Pharmacol Sci. 2018;22(13):4204-14. https://doi.org/10.26355/ eurrev_201807_15414.

18. Shang $\bar{W}$, Yang $\bar{Y}$, Zhang J, Wu Q. Long noncoding RNA BDNF-AS is a potential biomarker and regulates cancer development in human retinoblastoma. Biochem Biophys Res Commun. 2018;497(4):1142-8. https:// doi.org/10.1016/j.bbrc.2017.01.134 (ISSN 0006-291X).

19. Fabian ID, Onadim Z, Karaa E, et al. The management of retinoblastoma. Oncogene. 2018;37:1551-60. https://doi.org/10.1038/s41388-017-0050-x. 
20. Kim JW. Retinoblastoma. Int Ophthalmol Clin. 2015;55(1):77-96. https:// doi.org/10.1097/iio.0000000000000048.

21. Berry JL, Zolfaghari E, Chen A, Murphree AL, Jubran R, Kim JW. Optic nerve obscuration in retinoblastoma: a risk factor for optic nerve invasion? Ocul Oncol Pathol. 2017;3(4):283-91. https://doi.org/10.1159/00046 4468.

22. Rajasekaran S, Nagarajha Selvan LD, Dotts K, et al. Non-coding and coding transcriptional profiles are significantly altered in pediatric retinoblastoma tumors. Front Oncol. 2019:9:221. https://doi.org/10.3389/ fonc.2019.00221 (Published 2019 Apr 16).

23. Rao R, Honavar SG. Retinoblastoma. Indian J Pediatr. 2017;84:937-44. https://doi.org/10.1007/s12098-017-2395-0.

24. Dimaras H, Corson TW. Retinoblastoma, the visible CNS tumor: a review. J Neurosci Res. 2019;97(1):29-44. https://doi.org/10.1002/jnr.24213.

25. Plousiou M, Vannini I. Non-coding RNAs in retinoblastoma. Front Genet. 2019;10:1155. https://doi.org/10.3389/fgene.2019.01155 (Published 2019 Nov 14).

26. Zhao H, Diao C, Wang $X$, et al. LncRNA BDNF-AS inhibits proliferation, migration, invasion and EMT in oesophageal cancer cells by targeting miR-214. J Cell Mol Med. 2018;22(8):3729-39. https://doi.org/10.1111/ jcmm.13558 (published online ahead of print, 2018 Jun 12).

27. Zhang H, Liu C, Yan T, Wang J, Liang W. Long noncoding RNA BDNF-AS is downregulated in cervical cancer and has anti-cancer functions by negatively associating with BDNF. Arch Biochem Biophys. 2018;646:113.

28. Zhi H, Lian J. LncRNA BDNF-AS suppresses colorectal cancer cell proliferation and migration by epigenetically repressing GSK-3 $\beta$ expression. Cell Biochem Funct. 2019. https://doi.org/10.1002/cbf.3403.

29. Li W, Dou Z, We S, Zhu Z, Pan D, Jia Z, Liu H, Wang X, Yu G. Long noncoding RNA BDNF-AS is associated with clinical outcomes and has functional role in human prostate cancer. Biomed Pharmacother. 2018;102:1 105-10.

30. Huang Q, Yang J, He X, Shi S, Xing S. LncRNA BDNF-AS is associated with the malignant status and regulates cell proliferation and apoptosis in osteosarcoma. Biosci Rep. 2018;38(6):BSR20181498. https://doi. org/10.1042/bsr20181498 (Published 2018 Nov 15).

31. Esfandi F, Bouraghi H, Glassy MC, et al. Brain-derived neurotrophic factor downregulation in gastric cancer. J Cell Biochem. 2019;120:17831-7. https://doi.org/10.1002/jcb.29050.

32. Xu Y, Zhang G, Zou C, Zhang H, Gong Z, Wang W, Zhang W. LncRNA MT1.JP suppresses gastric cancer cell proliferation and migration through MT1.JP/MiR-214-3p/RUNX3 Axis. Cell Physiol Biochem. 2018;46(6):244559. https://doi.org/10.1159/000489651.

33. Zhang G, Li S, Lu J, et al. LncRNA MT1JP functions as a ceRNA in regulating FBXW7 through competitively binding to miR-92a-3p in gastric cancer. Mol Cancer. 2018;17(1):87. https://doi.org/10.1186/s12943-0180829-6 (Published 2018 May 2).

34. Zhu D, Zhang X, Lin Y, Liang S, Song Z, Dong C. MT1.JP inhibits tumorigenesis and enhances cisplatin sensitivity of breast cancer cells through competitively binding to miR-24-3p. Am J Transl Res. 2019;1 1(1):245-56 (Published 2019 Jan 15)

35. Yu H, Wang S, Zhu H, Rao D. LncRNA MT1.JP functions as a tumor suppressor via regulating miR-214-3p expression in bladder cancer. J Cell Physiol. 2019. https://doi.org/10.1002/jcp.28274.

36. Ma J, Yan H, Zhang J, Tan Y, Gu W. Long-chain non-coding RNA (IncRNA) MT1.JP suppresses biological activities of lung cancer by regulating miRNA-423-3p/Bim axis. Med Sci Monit. 2019;25:5114-26. https://doi. org/10.12659/msm.914387 (Published 2019 Jul 10)

\section{Publisher's Note}

Springer Nature remains neutral with regard to jurisdictional claims in published maps and institutional affiliations.
Ready to submit your research? Choose BMC and benefit from:

- fast, convenient online submission

- thorough peer review by experienced researchers in your field

- rapid publication on acceptance

- support for research data, including large and complex data types

- gold Open Access which fosters wider collaboration and increased citations

- maximum visibility for your research: over $100 \mathrm{M}$ website views per year

At BMC, research is always in progress.

Learn more biomedcentral.com/submissions 